\title{
Deciding when physicians are unfit to practise: an analysis of responsibilities, policy and practice in 11 European Union member states
}

\author{
Authors: Verena Struckmann, ${ }^{A}$ Dimitra Panteli, ${ }^{\mathrm{B}}$ Helena Legido-Quigley, ${ }^{\mathrm{C}}$ Isabelle Risso-Gill, ${ }^{\mathrm{D}}$ Martin McKee ${ }^{\mathrm{E}}$ and \\ Reinhard Busse ${ }^{F}$
}

In 1974, the European Economic Community established mutual recognition of medical qualifications obtained in any of its member states. Subsequently, a series of directives has elaborated on the initial provisions, with the most recent enacted in 2013. However, greater movement of physicians across borders and some high-profile scandals have raised questions about how to prevent a physician sanctioned in one country from simply moving to another, without undermining the principle of free movement. A survey of key informants in 11 European Union (EU) member states was supplemented by a review of peer-reviewed and grey literature, with the results validated by independent reviewers. It examined processes, adjudicative and disciplinary measures that are in place to evaluate physicians about whom concerns arise, and related sanctions, along with other aspects of professional standards and regulation. Overall, responses varied greatly between participating countries, with respect to the institutions responsible for the regulation of medical professions, the investigation processes in place, and the terminology used in each member state. While the types of sanction (removal from the register of medical professionals and/or licence revocation, suspension, dismissal, reprimand, warnings, fines, as well as additional education and training) applied are similar, both the roles of the individuals involved and the level of public disclosure of information vary considerably. However, some key features, such as the involvement of professional peers in disciplinary panels and the involvement of courts in criminal cases, are similar in most member states studied. Given the

Authors: Aresearch fellow, Department of Health Care Management, Berlin University of Technology, Berlin, Germany; Bresearch fellow, Department of Health Care Management, Berlin University of Technology, Berlin, Germany; ' associate professor, Saw Swee Hock School of Public Health, National University of Singapore, Singapore, and London School of Hygiene and Tropical Medicine, London, UK; Dresearch assistant, London School of Hygiene and Tropical Medicine, London, UK; Eprofessor, London School of Hygiene and Tropical Medicine, London, UK; Fprofessor, Department of Health Care Management, Berlin University of Technology, Berlin, Germany variation in the regulatory context, individuals and processes involved that is illustrated by our findings, a common understanding of definitions of what constitutes competence to practise, its impairment and its potential impact on patient safety becomes particularly important. Public disclosure of disciplinary outcomes is already applied by some member states, but additional measures should be considered to protect medical professionals from undue consequences.

KEYWORDS: Physician competence to practise, sanctions, disciplinary processes, litigation, Directive on Professional Qualifications, professional mobility, EU

\section{Introduction}

European legislation on the mutual recognition of various professional qualifications, such as those of physicians, dentists, pharmacists, nurses and midwives, has existed since 1974. In 2005, a directive on the recognition of professional qualifications (Directive 2005/36/EC) sought to bring the legislation up to date, especially with respect to training standards (Section 2, Articles 24-30); it was amended in 2013 by Directive 2013/55/EU. ${ }^{1}$ The new directive confirms the existing legislation in that a physician licensed in one European Union (EU) member state is deemed competent to practise in all others, but certain additional safeguards are introduced. These include: (i) a proactive alert mechanism authorising competent authorities in one member state to alert regulators in other member states about physicians whose right to practise has been revoked; (ii) the right for regulatory bodies to assess language competence of professionals from other member states (previously, it was left to employers to determine whether a physician had sufficient language skills to perform in the job in question); and (iii) a requirement that member states encourage continuing professional development (CPD) and continuing medical education (CME). Member states have until 18 January 2016 to transpose the new measures into national legislation.

The right to practise is conferred by licensing and/or registration, and can be lifelong or time limited. ${ }^{2}$ However, where a physician's actions fall short of certain standards imposed by national regulatory bodies, the physician may 


\section{Box 1. Terminology.}

Understandably, given the many languages in use within the EU and different beliefs about professional autonomy, the concept of fitness to practise, or competence to practise, is expressed in many different ways. Fitness to practise (FTP) has a specific regulatory meaning in Ireland, Malta and the UK. The term is defined as adhering to an extensive set of standards set out in a publication entitled Good medical practice ${ }^{9}$ covering professional performance and conduct. In this paper, we use the generic term 'competence to practise' as it is the most widely used alternative.

be subject to sanctions, including withdrawal of registration or licensing. Clearly, if registration/licensing is withdrawn, a physician loses the right to practise in another member state, although effective implementation depends on whether there are functioning notification systems - an issue about which there is persisting concern. ${ }^{3,4}$ However, employers and others may also have concerns about those subject to lesser sanctions, especially given several high-profile scandals. ${ }^{5,6}$ They should be guided by an understanding of the disciplinary processes in place in each member state but, so far, this has not been documented systematically - even though, as we have shown previously, there are substantial differences in how regulatory bodies deal with different issues and there is even considerable variation in terminology (Box 1). In this paper, we contribute to this process by comparing the policies, practices and processes that exist in 11 member states to assess continuing competence to practise. This paper is part of a series exploring professional standards across Europe and builds on earlier papers on licensing and registration processes ${ }^{7}$ and mechanisms to maintain professional competence. ${ }^{8}$

\section{Methods}

Key informants were identified in 11 member states (Austria, Estonia, Finland, Germany, Hungary, Malta, Romania, Slovenia, Spain, the Netherlands and the UK) with help from the UK General Medical Council (GMC), who also assisted with the design of a questionnaire that covered a range of issues related to regulation of professional standards. Issues related to processes in place when concerns about competence arise are listed in Box 2. Data collection was conducted in 2012. Information obtained from the questionnaires was supplemented with a review of peer-reviewed and grey literature. In 2014, a further set of independent experts from participating member states reviewed the data for accuracy and current validity. The main themes addressed relate to: defining physicians' competence to practise and its impairment; verifying and monitoring competence to practise; regulating and challenging physicians' competence to practise; investigating complaints, including adjudication processes and disciplinary panels; outcomes of disciplinary processes; and litigation.

\section{Results}

\section{Regulation, monitoring and impairment} of competence

In most of the member states studied (Estonia, Finland, Germany, Hungary, the Netherlands, Romania, Spain and the
Box 2. Main issues related to physicians' competence to practise addressed in the questionnaire.

> Competence: definition / standards / requirements / sanctions / reasons for impairment

> Redress: definition / insurance requirements / disciplinary basis / complaint type

> Medical regulation: purpose / underlying values / responsibility

> Responsible body: physician registration / licence to practise / redress

> Regulatory panels: composition / area of responsibility

> Healthcare regulatory bodies: relation / interaction / representation / organisations involved / functions / objectives

> Process: disciplinary procedures / processes of litigation / type of complaint / monitoring of physicians / characteristics of investigation / outcomes

UK), the primary aim of medical regulation was reported to be ensuring quality and safety of care. Other aims included fostering trust between physician and patient, safeguarding the freedom and reputation of the medical profession, and guaranteeing patients' freedom of choice. These aims were also set out in the texts of professional codes of conduct, where quality of care was most frequently mentioned, followed by honesty, integrity and patient safety. While there were some differences of emphasis between member states, they were not substantive. The institutions responsible for professional regulation of physicians vary between member states (Table 1). Some have a quasi-judicial function, such as the State Medical Chambers (Landesärztekammern - LÄK) in Germany, the Medical Council in Malta, and the GMC in the UK (acting through the Medical Practitioners Tribunal Service (MPTS), an independent adjudication body that considers all fitness-to-practise cases relating to physicians registered with the GMC).

Patients or their relatives are the usual source of concerns, with most informants estimating that they comprise 80-90\% of cases considered. In some countries (eg Finland, Malta and Slovenia), patient ombudsmen may also play a role, informing patients of their rights. Cases can also be brought to the attention of regulatory bodies in other ways. One is through organisations with an inspectorate role. Thus, the Dutch Health Care Inspectorate, although mainly responsible for safety and quality procedures within organisations, is also involved in oversight of physicians about whom concerns arise. In Austrian hospitals, the chief of the department or the hospital is responsible for monitoring physicians to ensure quality of care, while the Austrian Medical Chamber has established an Association for Quality Assurance and Quality Management in Medicine (ÖQMed) to oversee physicians practising in ambulatory care.

The commonest reasons for referral in all member states studied are criminal convictions, problems with performance, addiction or substance abuse potentially impairing performance and/or judgement, and unethical behaviour. Only two of the member states included in the study (Spain and the UK) reported that they also consider sanctions previously imposed in a different member state in their judgement. 
Table 1. Institutions responsible for the regulation of medical professions in the 11 member states studied.

\begin{tabular}{|c|c|c|c|}
\hline Member state & Institution with main responsibility & $\begin{array}{l}\text { Institution with } \\
\text { responsibility for less } \\
\text { severe sanctions }\end{array}$ & $\begin{array}{l}\text { Institution with responsibility for } \\
\text { severe sanctions }\end{array}$ \\
\hline Austria & Federal Ministry of Health & $\begin{array}{l}\text { Austrian Medical Chamber } \\
\text { and the employer }\end{array}$ & $\begin{array}{l}\text { Austrian Medical Chamber and the } \\
\text { administrative court }\end{array}$ \\
\hline Estonia & Ministry of Social Affairs (Estonian Health Board) & The employer & The court \\
\hline Finland & $\begin{array}{l}\text { Valvira (National Supervisory Authority for } \\
\text { Welfare and Health) }\end{array}$ & $\begin{array}{l}\text { Valvira and Regional State } \\
\text { Administrative Agencies }\end{array}$ & Valvira and the court \\
\hline Germany & $\begin{array}{l}\text { LÄK (State Medical Chamber) and office for } \\
\text { approbation }\end{array}$ & $\begin{array}{l}\text { The professional court and } \\
\text { medical chambers }\end{array}$ & $\begin{array}{l}\text { Office for approbation and the } \\
\text { administrative court }\end{array}$ \\
\hline Hungary & $\begin{array}{l}\text { Ministry of Health (Office of Health Authorization } \\
\text { and Administrative Procedures) and National } \\
\text { Institute for Quality and Organizational } \\
\text { Development in Healthcare and Medicines }\end{array}$ & The court & The court \\
\hline Malta & Medical Council of Malta & The employer & Court of Justice and Medical Council \\
\hline The Netherlands & $\begin{array}{l}\text { KNMG (The Royal Dutch Medical Association) } \\
\text { and disciplinary boards }\end{array}$ & $\begin{array}{l}\text { Inspectorate and the board } \\
\text { of directors of a hospital }\end{array}$ & Disciplinary boards \\
\hline Romania & CMR (Romanian College of Physicians) & $\begin{array}{l}\text { Discipline Commission of } \\
\text { the Romanian College of } \\
\text { Physicians }\end{array}$ & $\begin{array}{l}\text { Discipline Commission of the } \\
\text { Romanian College of Physicians }\end{array}$ \\
\hline Slovenia & Medical Chamber & Medical Chamber & The court of the Medical Chamber \\
\hline Spain & Ministry of Health & The employer & The employer or the court \\
\hline UK & GMC & The GMC case examiners & MPTS, IOP and MPTS FTP panel \\
\hline
\end{tabular}

\section{Investigating complaints and disciplinary panels}

The data on the number and nature of complaints considered per year in each member state were very fragmented and the numbers given varied enormously (from 7 to 11,000 per year), indicating substantial variation in thresholds, even allowing for differences in numbers of registered physicians. Data on the number of complaints leading to disciplinary action were also either unavailable or not easily comparable, as was information on the number of physicians whose right to practise was suspended or removed following disciplinary action.

Investigation processes vary substantially according to the structures in place and the body responsible in each member state. In the UK, the Medical Act mandates the GMC to investigate when serious concerns arise about a physician's fitness to practise medicine. Following investigation of these concerns, any decisions to require undertakings or impose a sanction, interim order or warning are made known to the regulator in the country in which the physician qualified and in any country in which the physician holds a registered address. In addition, the GMC sends a general monthly circular of recent fitness-to-practise decisions to a list of overseas regulatory authorities that have requested this. Concurrently, a physician's employer may also investigate complaints and take action at a local level, which may lead to civil litigation proceedings. In contrast, in Hungary it is the employer, such as the hospital where the complaint arose, that first investigates complaints (within 30 days). If the matter cannot be resolved within the hospital, then the complaint moves into the judicial arena. The employer or the complainant will seek a remedy in the court, although this may be resolved by an out-of-court settlement. It is reported that between 400 and 500 cases reach the courts each year, while approximately one-third of doctors have been taken to court and a further $40 \%$ threatened with action.

Unsurprisingly, the medical profession is represented on disciplinary panels summoned for physicians whose competence to practise is questioned in almost all participating member states (Austria, Finland, Germany, Hungary, Malta, the Netherlands, Romania, Slovenia, Spain and the UK), regardless of the mechanism and institution responsible. However, the exact panel composition varies. While in Finland, Germany and the Netherlands only legal experts and health professionals in related specialties are involved, in Malta and the UK panels also include lay people. Some countries (Estonia, Finland, Hungary, Slovenia and Spain) reported that external experts are occasionally included in the process. This usually happens when specific questions arise that are beyond the panel's expertise. In Slovenia, members of the panel are always external to the institution where the incident concerned took place.

\section{Outcomes of disciplinary processes}

As reported by participating member states, outcomes of disciplinary processes related to physicians whose competence to practise was found to be impaired can be categorised according to a pyramid depending on severity (Fig 1). The strongest disciplinary sanctions include removal from the register of medical professionals and/or licence revocation, 


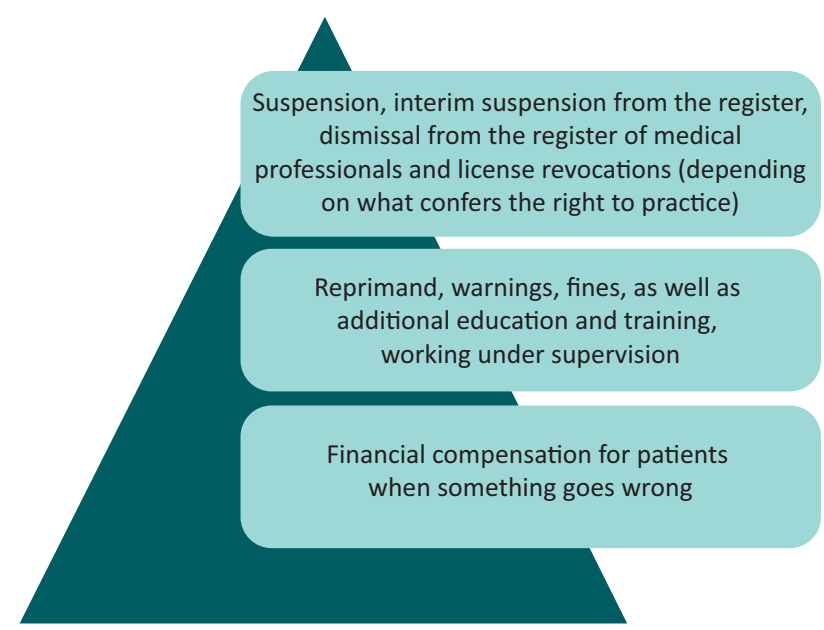

Fig 1. The pyramid of regulatory outcomes of disciplinary processes.

suspension, dismissal and reprimand (depending on what confers the right to practise). Less severe measures can take the form of warnings or fines, as well as additional education and training. Moreover, patients have the right to obtain financial compensation when something goes wrong. Institutions responsible for the different sanctions are listed in Table 1.

Uniquely among participating member states, Spain offers psychological or psychiatric support measures for physicians undergoing competence-to-practise investigations. Sanctioned physicians are able to continue to practise under supervision until the case is completed.

The attitude of a physician during investigation seems to affect decisions at least in Finland and the Netherlands: an admission of guilt might lead to mitigated punishment if the physician commits to positive corrective measures and an improvement is a realistic option. Similarly, in the UK, consideration is given to a physician's attitude and insight when deciding on the appropriate action to protect the public and uphold confidence in physicians.

Physicians under investigation can continue to practise in the majority of participating member states (Austria, Finland, Germany, Hungary, the Netherlands, Slovenia, Spain and the UK) until the case has been completed. In most member states surveyed, with the exceptions of Romania, Spain and Slovenia, decisions related to disciplinary action are made public.

In Slovenia, decisions short of suspension are communicated only to the parties involved, the competent authorities and those who raised concerns (justified as protecting patients and physicians alike, as documentation may contain confidential data such as medical histories). However, decisions that involve suspension or other removal of the right to practise are all communicated to the Ministry of Health and the employer. In Romania, the decision is communicated to the physician and the Executive Board of the Romanian College of Physicians. In Germany, decisions are made public to a certain extent: only those cases heard in courts dealing with professional conduct can be made public by the medical chambers; the decision also appears in the professional journal Deutsches Ärzteblatt. Complaints not reaching the courts remain confidential.

\section{The role of litigation}

The role of courts varies considerably among participating member states. However, in all cases they are the setting for litigation in cases of impaired competence that extend beyond strictly professional matters, such as criminal offences.

Court involvement in settling professional issues depends on the member state's regulatory framework. Processes differ, but they invariably begin with a claim that is filed with a general or civil court. Moreover, the parties initiating legal proceedings vary, along with the type of court charged with final decisionmaking power. This variation will be illustrated using the examples of Hungary, Germany, Spain and the UK.

In Hungary, the process begins once a patient has lodged a claim with the patient advocate in the health facility or at the financing body of the provider, such as local government or the National Public Health and Medical Officer Service. After an initial investigation, two options are possible: either an out-of-court agreement or litigation. Disciplinary measures can be decided only by the court. If the patient complaint can be resolved out of court, the employer might prescribe some training and warnings.

In Germany, the entire process depends on the legal framework in which the physician works, and uses procedures either under the professional code or under the Federal Medical Code (Bundesärzteordnung). Arbitration procedures in cases of treatment errors - which can be initiated by patients, their representatives, physicians or insurers - are carried out separately and the results are non-binding. Patients are free to take the case further if they do not agree with the outcome and can choose whether they appeal to an arbitration board or file a claim directly with a court. Different types of court can be involved. Professional courts deal with breaches of the professional code of conduct. The right to practise can be revoked only by the licensing authority and, in this case, the action is heard in the administrative court.

In Spain, the process is initiated once a patient complaint is forwarded to the board of the medical association. A physician is appointed to work with a law firm and, when necessary, an ethics committee. They propose a sanction to the Board, which then decides on the final outcome. Patients also have the option of a court hearing.

Finally, in the UK, the courts do not become involved in decisions about the right to practise unless the physician seeks to overturn an adverse decision by means of judicial review, seeking to show that it was unreasonable. The courts do become involved in cases of clinical negligence, where they establish liability and damages. They also inform the GMC of doctors who receive criminal convictions.

\section{Discussion}

The amended version of the Professional Qualifications Directive includes concrete steps to regulate the ability of health professionals to practise safely and in the interest of the patient within the EU. This paper seeks to describe some of the processes that are used when concerns arise about a physician's competence to practise, as well as some types and routes of disciplinary action.

There is no obvious correlation between the type of institution involved and the severity of measures imposed, 
suggesting that, despite considerable differences, a convergence of disciplinary approaches might be feasible. However, RissoGill et a $l^{10}$ noted how regulatory institutions with broader remits, such as those in Austria, Germany and the UK, reported employing severe sanctions more frequently when presented with a range of examples of professional misconduct. Furthermore, the variability of disciplinary processes found in participating member states implies that a harmonisation of procedures across the board would require detailed analysis of existing structures and the inclusion of alternative options where fundamental differences exist. While the types of sanction applied can be categorised within a common system (Fig 1), both the participants involved and the level of public disclosure of information vary considerably. Nevertheless, public involvement in monitoring professional practice should be central to the regulatory process, not least to ensure that patient rights are upheld. Thus, there is a strong case to be made for greater transparency in many of the systems described here. Caution is also necessary in order to recognise the importance of system-level factors when problems arise and to avoid singling out individuals inappropriately for blame.

Taking into consideration both the growing number of physicians crossing borders and the disquieting cases of sanctioned practitioners continuing to work in different countries, it is crucial that relevant information from a physician's previous country of employment is made available to the appropriate authorities. The amended version of the Professional Qualifications Directive introduces an alert system, via which member states can notify relevant authorities in other member states when a physician's right to practise has been removed (new Article 56a). However, it is important for member states to recognise the need for a common understanding of terminology and concepts related to situations in which a physician is considered not competent to work.

Finally, it is interesting to consider possible pathways towards ensuring more affirmative approaches to physicians' competence to practise, with the intention of improving patient safety and quality of care in the future. Previous work ${ }^{8}$ has shown that no uniform approach to actively maintaining competence could be identified among participating member states. However, CPD and CME are generally recognised as key requirements for maintaining professional standards. This is in line with the amended version of the Professional Qualifications Directive, which recommends that CPD, as a means of maintaining competence to practise, becomes a binding principle for medical professionals in Europe (new Article 22.1.b) and that coordinators of competent authorities at the member state level 'exchange information and best practice for the purpose of optimising continuous professional development in member states' (new Article 56.4).

\section{Limitations}

A common problem with questionnaire studies is the validity of data. Some of the answers to the questionnaire were incomplete, outdated or completely missing. Variation in terminology between member states also posed a substantial problem. The data were verified with national reviewers and triangulated with other data sources to overcome these inconsistencies.

\section{Conclusion}

The amended version of the Professional Qualifications Directive includes specific measures that will facilitate the exchange of information on physicians' competence to practise among member states. This is an important first step in ensuring patient safety in the face of increased professional mobility. Given the variation in regulatory context, participants and processes involved, a common understanding of definitions of what constitutes competence to practise, its impairment and its potential impact on patient safety becomes particularly important. Public disclosure of disciplinary outcomes is already in place in some member states, but not all. Moreover, consideration of the need to protect vulnerable professionals may also be important, such as the psychological support offered in Spain.

\section{Acknowledgements}

We thank all questionnaire respondents who generously took time to provide us with the requested information. We particularly wish to thank all the institutions participating in the study: LSE Health (the UK), London School of Hygiene and Tropical Medicine (the UK), European Observatory on Health Systems and Policies (Belgium), European Social Observatory (Belgium), Technische Universität Berlin (Germany), Maastricht University (the Netherlands), European Centre for Social Welfare Policy and Research (Austria), National Institute of Public Health of the Republic of Slovenia, Universitat de Barcelona (Spain), PRAXIS Center for Policy Studies (Estonia), National Research and Development Centre for Welfare and Health (Finland), and Semmelweis University, Health Services Management Training Centre (Hungary).

We wish to thank the independent country reviewers who took time to double-check the manuscript thoroughly: Austria - Herwig Ostermann, Gesundheit Österreich GmbH, AL Gesundheitsökonomie; Estonia - Priit Kruus, health policy analyst and acting director of Health Policy Programme Praxis - Centre for Policy Studies; Finland - Liina-Kaisa Tynkkynen, University of Tampere / School of Health Sciences; Germany - Dr Med Ramin Parsa-Parsi, MPH, Bundesärztekammer, Dezernat für Internationale Angelegenheiten; Hungary - Dr Eszter Kovács, Health Services Management Training Centre, Semmelweis University; Malta - Dr Natasha Azzopardi Muscat, consultant, Public Health Directorate for Health Information and Research, Ministry for Energy and Health, and lecturer, Department of Health Services Management, Faculty of Health Sciences, University of Malta, and Dr Conrad Azzopardi, consultant, general medicine, Department of Primary Care, Ministry for Energy and Health; Romania - Marius Ungureanu, research assistant, Cluj School of Public Health and College of Political, Administrative and Communication Sciences, Babeş-Bolyai University; Slovenia - Dr Eva Turk, senior researcher, DNV GL Strategic Research and Innovation, Healthcare Programme; Spain - Sergio Minue, head of Health Policy and Ethics Department, Andalusian School of Public Health; the Netherlands - Prof Dr Roland Friele, Deputy Director NIVEL, head of Research Department; the UK - Anna Rowland, assistant director, policy and planning, GMC.

\section{Funding}

This paper is the result of research requested by the European Commission's Directorate-General for Health and Consumers and is co-funded through the EU's FP7 Cooperation Work Programme: Health (contract number 242058; contract acronym EUCBCC). The European Commission is not responsible for the content of the paper. Responsibility for the facts described in the report and the views expressed rests entirely with the authors. 


\section{References}

1 European Parliament. Directive 2013/55/EU of the European Parliament and of the Council of 20 November 2013 amending Directive 2005/36/EC on the recognition of professional qualifications and Regulation (EU) No 1024/2012 on administrative cooperation through the Internal Market Information System ('the IMI Regulation'). Off J Eur Union 2013;L354:132-71.

2 Merkur S, Mossialos E, Long M, McKee M. Physician revalidation in Europe. Clin Med 2008;8:371-6.

3 de Vries H, Sanderson P, Janta B et al. International comparison of ten medical regulatory systems: Egypt, Germany, Greece, India, Italy, Nigeria, Pakistan, Poland, South Africa and Spain. Cambridge, UK: RAND, 2009.

4 van Ginneken E, Busse R. Cross-border health care data. In: Wismar M, Palm W, Figueras J, Ernst K, van Ginneken E (eds), Cross-border health care in the European Union: Mapping and analysing practices and policies. Brussels: European Observatory on Health Systems and Policies, 2011:289-340.

5 Simpson JM, Esmail A. The UK's dysfunctional relationship with medical migrants: the Daniel Ubani case and reform of out-ofhours services. Br J Gen Pract 2011;61:208-11.
6 Wismar M, Maier CB, Glinos IA, Dussault G, Figueras J, editors. Health professional mobility and health systems: Evidence from 17 European countries. Brussels: European Observatory on Health Systems and Policies, 2011.

7 Kovacs E, Schmidt AE, Szocska G et al. Licensing procedures and registration of medical doctors in the European Union. Clin Med 2014;14:229-38.

8 Solé M, Panteli D, Risso-Gill I et al. How do medical doctors in the European Union demonstrate that they continue to meet criteria for registration and licencing? Clin Med 2014;14:633-9.

9 General Medical Council. Good medical practice. London: GMC, 2013.

10 Risso-Gill I, Kiasuwa R, Baeten R et al. Exploring the scope of practice and training of obstetricians and gynaecologists in England, Italy and Belgium: a qualitative study. Eur J Obstet Gynecol Reprod Biol 2014;180:40-5.

Address for correspondence: Ms V Struckmann, Department of Health Care Management, Berlin University of Technology, Berlin, Germany.

Email: verena.struckmann@tu-berlin.de

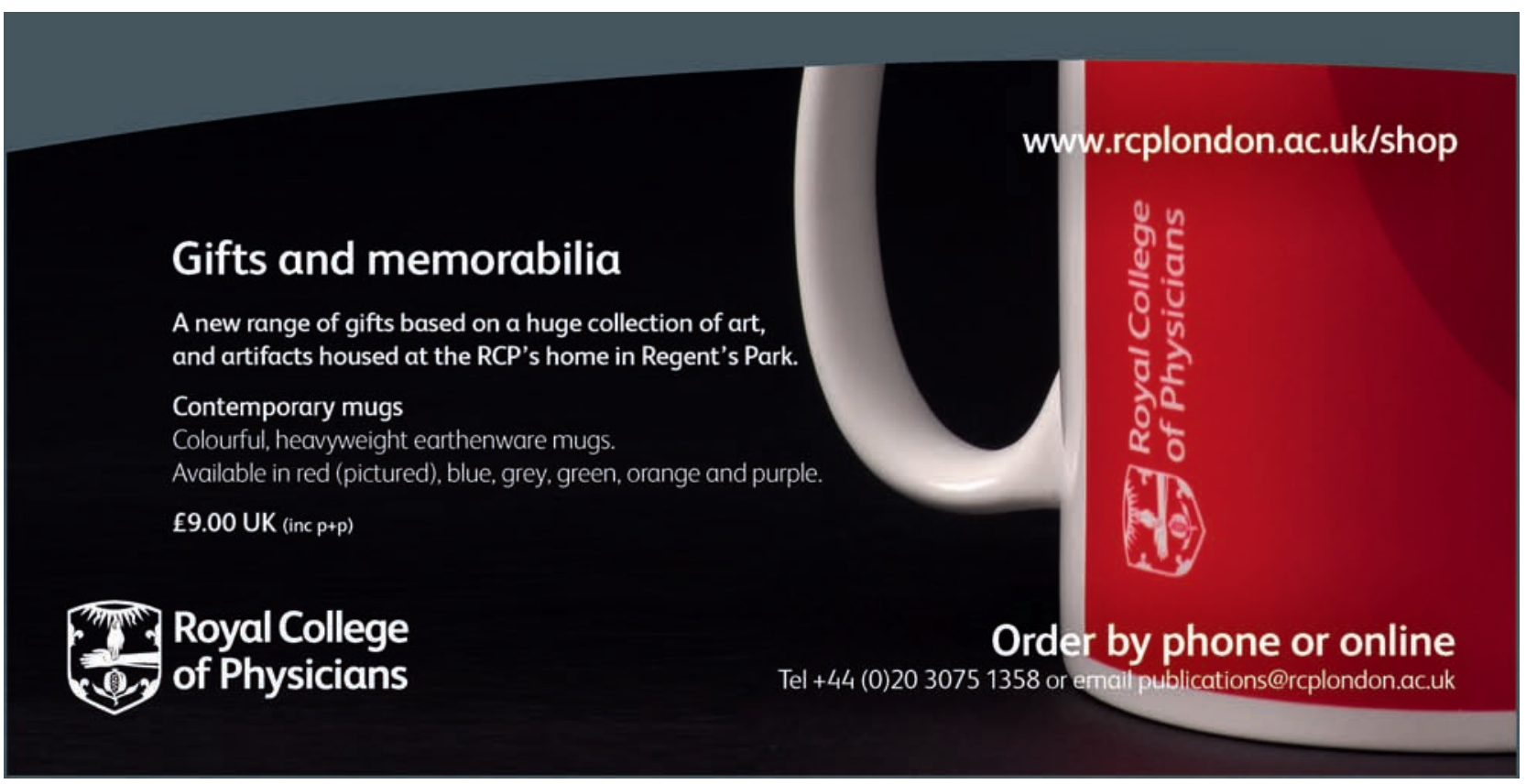

